\title{
Return of EMT to the Land Downunder: TEMTIA-VII, Melbourne, 2015
}

\author{
Donald F. Newgreen $^{a, b}$ Erik W. Thompson ${ }^{c, d}$ \\ ${ }^{a}$ Murdoch Childrens Research Institute, and b University of Melbourne Department of Pediatrics, Royal Children's \\ Hospital, Melbourne, VIC, and 'Institute of Health and Biomedical Innovation, School of Biomedical Sciences, \\ Queensland University of Technology, and ${ }^{\mathrm{d}}$ Translational Research Institute, Brisbane, QLD, Australia
}

The seventh international Epithelial-Mesenchymal Transition (EMT) Conference, hosted by The EMT International Association (TEMTIA), was held in Melbourne, Australia, from the 11th to 14th October, 2015. This TEMTIA-VII conference therefore returned to its country of origin: in 2003 TEMTIA-I was held in Port Douglas, QLD, Australia. At that first meeting a 30-min session was assigned to discussing the possibility of a future meeting - this was decided in about 30 seconds! In the intervening years, the TEMTIA conferences have been held biennially in Vancouver, BC, Canada (2005), Krakow, Poland (2007), Tucson, AZ, USA (2009), Singapore (2011), and Alicante, Spain (2013). The 8th TEMTIA meeting is planned for Houston, TX, USA, in December 2017 (conveners Raghu Kalluri and Jing Yang), and the 9th in Kumamoto, Japan, in 2019 (convener Guojun Sheng). The TEMTIA meetings provide integrated updates and continuity to the EMT field.

TEMTIA-VII was convened by Rik Thompson and Don Newgreen, as for the inaugural meeting, with an Australasian Organizing Committee of Judith Clements, Michael Eccles, Yeesim Khew-Goodall, Guy Lyons, Michael Murray, Steven Mutsaers, Sudha Rao, Joy Rathjen, Nadia Rosenthal, Christobel Saunders, Elizabeth Vincan, and Elizabeth Williams. The International Organizing Committee comprised Marianne Bronner, Shoukat Dedhar, John Haley, Maria Leptin, Angela Nieto Toledano,

\section{KARGER}

(c) 2017 S. Karger AG, Basel

E-Mail karger@karger.com

www.karger.com/cto
Klaus Pantel, Duanqing Pei, Ray Runyan, Pierre Savagner, Guojun Sheng, Yoshiko Takahashi, Jean Paul Thiery, and Bob Weinberg. The conference was organized by Ros Barrett-Lennard of Magic Touch Consultancies, and the conference program can be found at http://www. emtmeeting.org/TEMTIA-VII_program.htm.

EMT, a unifying concept first advanced by the late Professor Elizabeth (Betty) Hay (1927-2007), is important in biological processes such as embryonic development, cancer dissemination, and wound healing. Over recent years, EMT has expanded to illuminate stem cell biology and fibrosis, and because of the diversity of examples, models, methods, and fields assembled under the broad EMT heading, all the TEMTIA meetings have been intentionally cross-disciplinary, with single sessions to virtually ensure, for example, cancer biologists share time with developmental and systems biologists. In addition, over the period of TEMTIA's existence the EMT field has exploded, and has therefore been confronted by the difficulties that arise from success: of "big data" and complex systems biology. The recent TEMTIA meetings have identified these emerging trends, including the positive impact that new methods of systems analysis can have in

Donald F. Newgreen

Embryology Laboratory, Cell Biology Theme, Murdoch Childrens Research Institute Royal Children's Hospital

Parkville, VIC 3052 (Australia)

E-Mail don.newgreen@mcri.edu.au

Erik W. Thompson

Institute of Health and Biomedical Innovation, School of Biomedical Sciences

Queensland University of Technology, TRI Rm 7031, 37 Kent Street

Woolloongabba, QLD 4102 (Australia)

E-Mail e2.thompson@qut.edu.au 
identifying novel regulators of EMT and the utility of mathematical models in identifying potential impacts of EMT on the emergent behavior of tissues and in discriminating between stochastic and deterministic processes. Another theme that emerged more strongly in this meeting was the interplay between the immune system and cells undergoing EMT, with several talks, including the Betty Hay Award lecture, addressing the role of such interactions in pathological processes. Indeed, evidence of EMT signaling in immune cells was also presented.

Rather than the traditional bastions of development, such as cancer, fibrosis, wound healing, etc., the TEMTIA-VII session themes were based on concepts such as plasticity, stemness and self-renewal, signalling networks and transcription factors, and systems biology, in order to further stimulate cross-disciplinary interactions within each session. In addition, as the EMT field has evolved, areas directly relevant to health, such as cancer invasion and fibrosis, have extended gradually towards therapeutic applications. For this reason, TEMTIA-VII devoted sessions to clinical applications, and the meeting was fortunate to incorporate a shared session with the 2 nd Thomas Ashworth Circulating Tumour Cell Symposium organized by Kevin Spring, which focused on disseminating tumour cells, thereby bridging the disciplines of the basic science of EMT and clinical oncology. Over 200 attendees from all over the world [22 countries; Europe (39), the Americas and Canada (24), Asia (17), and Australia and New Zealand (130)], including 31 early career researchers and 43 students, took part in the meeting.

As well as retaining areas of strength from previous TEMTIA meetings, in this year's meeting an Early Career Researcher Forum preceded the main program. This enabled 12 young investigators to present their work in front of an audience of other early career researchers and experienced researchers. The standard of this section was exceptionally high and feedback was positive on the opportunity that this offered younger researchers to participate from the podium in this international meeting. This important adjunct was organized by ECR researchers Annette Shewan, Philip Gregory, Caroline Ford, and Allan Burrows, with guidance from Mike Murray from the LOC.

The meeting included 2 plenary lectures; Prof. Jean Paul Thiery (IMCB, Singapore) delivered an exciting presentation, weaving together many aspects of EMT and its historical background, while Prof. Caroline Dive (CRUK Institute, UK) delivered the Circulating Tumour Cell Symposium Plenary Lecture in the shared CTC session.

Two talks named in honour of the late Betty Hay were highlights of TEMTIA-VII. Prof. Masatoshi Takeichi from the RIKEN Center for Developmental Biology in Kobe, Japan, who discovered the cadherin family of cell adhesion molecules that are central to the EMT, gave the Betty Hay Oration, an enlightening talk on the regulation of cell-cell adhesion in epithelia. Claudia Palena, from $\mathrm{NIH}$, received the Betty Hay Award for an outstanding young female scientist and spoke about her work on priming the immune system against pro-EMT transcription factors as a potential cancer therapy. Jean Paul Thiery (France) presented The EMBO Plenary Lecture on the understanding of carcinoma dissemination for the design of new therapeutic strategies. Keynote speakers included Jane Visvader (Australia), Marianne Bronner (USA), Angela Nieto (Spain), Richard Harvey (Australia), Roberto Mayor (UK), Sandra Peiro (Spain), Greg Goodall (Australia), Erica Golemis (USA), and invited speakers were Claudia Palena (USA), Steve Frisch (USA), Amparo Cano (Spain), Arial Zeng (China), Guojun Sheng (Japan), James Osborne (UK), Arjun Deb (USA), Patrick Humbert (Australia), and Melissa Davis (Australia). During the dinner, Ray Runyan (USA) gave an entertaining and informative perspective on the history of EMT research.

In this selection of papers for Cells Tissues Organs from the TEMTIA-VII program, we have included the molecular biology of EMT in development using the tractable fly model: "The Role of Netrins and Their Receptors in Epithelial Mesenchymal Plasticity during Development" by Michael Murray. A novel role for 1 of the recurrent molecular motifs of EMT is explored in "The Snail Family in Normal and Malignant Hematopoiesis" by Catherine Carmichael and Jody Haigh, while JoMaree Courtney and Patricia Spafford probe another clinical EMT function in "The Role of Epithelial-Mesenchymal Transition in Chronic Obstructive Pulmonary Disease." The sometimes counterintuitive emergent properties derived from mathematical models is explored in "Differential Clonal Expansion in an Invading Cell Population: Clonal Advantage or Dumb Luck?" by Donald Newgreen, Dongcheng Zhang, Bevan Cheeseman, Benjamin Binder and Kerry Landman. Two papers directly address the therapeutic implications of EMT research. These are "Therapeutic Targeting of Epithelial Plasticity Programs - Focus on the Epithelial-Mesenchymal Transition” by Reem Malek, Hailun Wang, Kekoa Taparra, and Phuoc Tran, and the Betty Hay Award-winning "Development of Cancer Vaccines Targeting Brachyury, a Transcription Factor Associated with Tumor EMT" by Duane Hamilton, Justin David, Charli Dominguez, and Claudia Palena. 